\title{
Impact of Microgrid on Power System Voltage Stability
}

\author{
Burak YILDIRIM ${ }^{1}$, Muhsin Tunay GENÇOĞLU²
}

\begin{abstract}
The energy demand of the modern society we live in is increasing day by day. Existing power systems are faced with many problems. Microgrids (MG), which have an important place in solving these problems, cause many changes in power systems. Therefore, examine the effects of MGs on power systems is very important. In this publication study, the effects of a MG on power system voltage stability are shown. In this publication study, the effects of a MG on power system voltage stability are shown. To demonstrate this effect, an IEEE 14 bus test system was used. The designed MG is integrated into the IEEE 14 bus power system. The effect of MG on the voltage stability is shown in terms of dynamic voltage stability. For this purpose, fault scenarios have been realized in the test system. The results also showed that integrating MG into power systems provided positive effects on the system in terms of voltage stability.
\end{abstract}

Keywords_Microgrid, Voltage stability, Time domain analysis

\section{INTRODUCTION}

The energy demand of the modern society we live in is increasing day by day. Our fossil resources used for energy generation are irreversibly reduced. In addition, the plants that use these fuels are giving serious damages to our world. Increasing worries for energy availability and the aging infrastructure of current electricity distribution and transmission networks are increasingly challenging the safety, reliability and quality of power supply. In addition, the existing network infrastructure in developing countries is particularly suffered from various problems such as the high cost to expand and the need to increase the efficiency of the existing network. A significant amount of investments will be necessary to overcome and improve these infrastructures, while a much more effective way of meeting social needs is to combine innovative solutions, technologies and network structures. The network connections of renewable energy sources (RES) can provide solutions to these problems. But their existing variable nature leads to difficulties in network integration $[1,2]$

Distributed generation resources (DGR), including RESs within the MG, can help manage the variability of RESs, improve power-system capacity limits, reduce emission rates, increase efficiency. Distributed generation (DG) can be defined as the type of generation that can generate power

${ }^{1}$ Burak YILDIRIM, Bingol University, Bingol, Turkey, Email: burak0225@hotmail.com

${ }^{2}$ Muhsin Tunay GENÇOĞLU, Firat University, Elaziğ, Turkey, Email: mtgencoglu@firat.edu.tr locally at the distribution voltage level and can use RESs. The MG can be defined as a set of storage systems, loads, control systems and DGs that are seen as a sub-system of the distributed network [1,3]. The MG can be operated in both grid mode and island mode depending on factors such as economic benefits, network interruptions or planned interruptions. The island mode is very important because when the power quality from the network falls below normal standards, the MG will deliberately be disconnected from the network and will supply power the sensitive loads independently. In this way, it can greatly increase the reliability of the power supply. However, in island operations, the voltage and frequency of the MG can only be protected by a variety of DGs. For this reason, the dynamic response behavior of the island-mode MG depends on the characteristics of the DGs and the control mode of their interface with the network [3].

Voltage stability is defined as the protection of the steady voltage value of all buses after a power system has encountered any disturbing effect while in a given initial condition. Voltage instability can lead to the consequences of a progressive decrease or increase in the voltage of some buses [4]. Power system voltage stability is a mandatory issue for operating and planning the safe, reliable, efficient and economical of power systems. This issue has usually been studied in the literature as static and dynamic voltage stability [5].

There are many papers in the literature on dynamic voltage stability of power systems. There are also many papers in the literature that examine islanded mode MG's stability. But as a result of integrating MG systems into the power systems, the number of papers that examine the changes in the voltage stability of the power system is very limited. This paper was created for this reason.

The sections of this study are organized as follows. In Chapter 2, the topic of dynamic voltage stability is explained. In Chapter 3, The MG system that we have studied effect on the power system is described. Chapter 4 contains the simulation results. Finally, Chapter 5 presents the result of this study.

\section{II.DYNAMIC VOLTAGE STABILITY}

Voltage stability is the ability of a power system to keep the voltage values in all buses within the given limits in normal operating times and after encountering a disturbance. This sustainability can be assessed against a small or large 
disturbance, and at the same time it can be examined short or long time after the disturbance has occurred [4, 5].

Power system voltage stability studies are usually done in static and dynamic forms in the literature. The dynamic voltage stability of the power system is not possible to evaluate with the static form corresponding to long-term stability evaluations involving power flow studies. In dynamic form, time domain simulation is used with dynamic models of generators, loads, automatic voltage regulators, and other components of the power system. Both short-term and longterm voltage stability evaluations are performed with dynamic form [5].

The algebraic and state variables that form the system in the time domain simulation is always evaluated step by step each time step. The block diagram of Time domain integration is given in figure 1 [6].

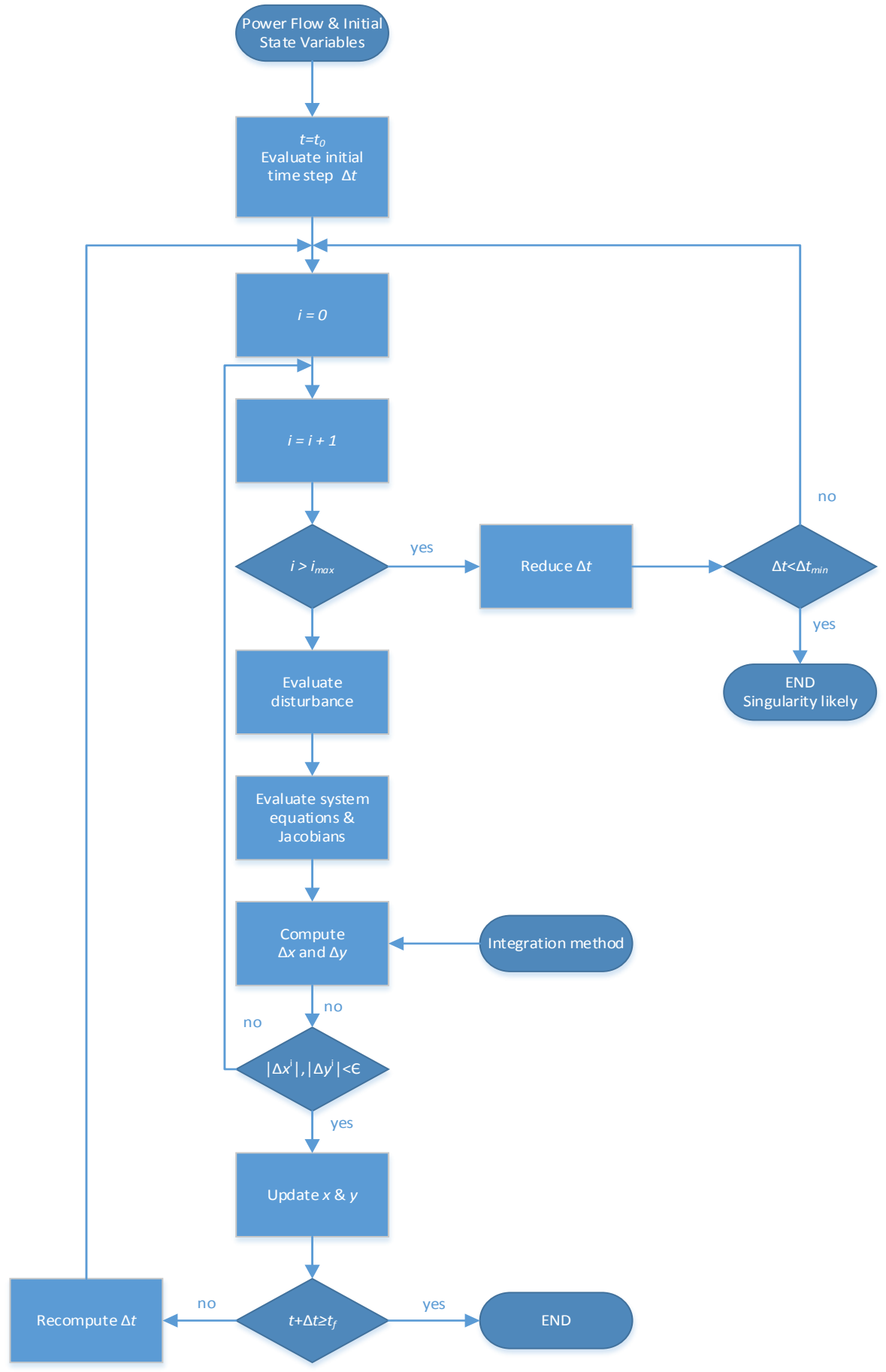

Fig. 1. Time integration method diagram

\section{Micro GRID (MG)}

The concept of smart grids refers to the development of electricity networks. Smart grid is an electrical network that intelligently integrates all user actions connected to the network for continuous, economical and secure electricity distribution. The realization of active distribution networks requires the application of new system concepts. In addition, 
MGs, which are described as "building blocks of intelligent networks", are perhaps the most promising new network structure. The MG organization includes DGs containing micro-generations with distribution-level storage devices and controllable loads [2].

The usage rates of MG and DG units in electric power systems are increasing day by day. The main reasons for this are; short construction time of the plant, different source options, improved power quality, reduced transmission losses and increased system reliability. In addition, the use of renewable energy sources as DG sources have also given a great impetus to this increase [7].

\section{A. Wind Model}

Wind energy conversion systems (WECS) are systems that convert wind energy into electrical energy. The wind turbine captures the kinetic energy of the wind flow through the rotor blades and transfers energy to the induction generator via the gearbox. The generator shaft is driven by the wind turbine to generate electricity. The task of the gearbox is to convert the slow speed of the wind turbine into high speed on the induction generator side. Output voltage and frequency are kept within the specified range using inspection, measuring, control and protection techniques. The wind turbines may have a horizontal axis configuration or a vertical axis configuration. While the average commercial turbine size of the WECS was $300 \mathrm{~kW}$ in the 1990s, recently large capacity machines have been developed to $5 \mathrm{MW}$. The output power of a wind turbine is determined by various factors such as wind speed, turbine size, and turbine shape:

$P=\frac{1}{2} C_{p} \rho V^{3} A$

Where $\mathrm{P}$ is the power (W), $\mathrm{C}_{\mathrm{p}}$ is the power coefficient, $\rho$ is the air density $\left(\mathrm{kg} / \mathrm{m}^{3}\right), \mathrm{V}$ is the wind speed $(\mathrm{m} / \mathrm{s})$ and $\mathrm{A}$ is the sweeping area of rotor blades $\left(\mathrm{m}^{2}\right)$. The power coefficient, $\mathrm{C}_{\mathrm{p}}$, measures the amount of energy obtained by the rotor of the wind turbine[8]. Figure 2 shows the block diagram of the WECS section of the MG used in the study. The equations and definitions of this WECS system can be found in $[9,10]$.

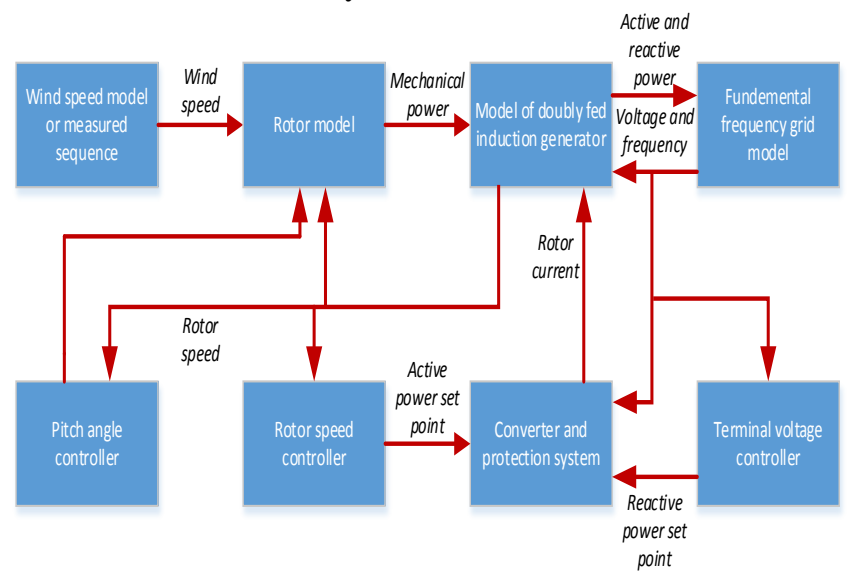

Fig 2. WECS model block diagram

\section{B. PV Model}

Photovoltaic technology is a solar energy technology that uses solar cells or photovoltaic arrays to convert sunlight into electrical energy. Figure 3 shows the equivalent circuit of a PV cell.

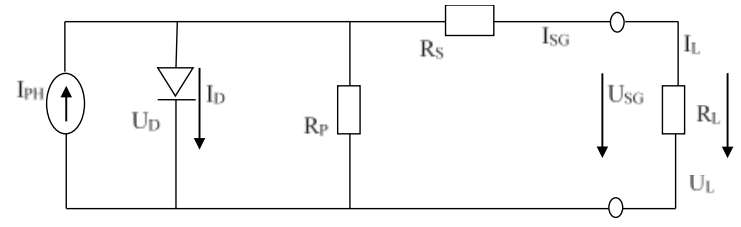

Fig 3: Equivalent circuit of the photovoltaic cell

$I_{P H}$ : Light current of solar cell, $I_{D}, U_{D}$ : Internal current and voltage of P-N diode,

$R_{P}$ : Parallel resistor, $R_{S}$ : Serial resistance, $I_{S G}, U_{S G}$ : Current and voltage of PV

$R_{L}, I_{L}, U_{L}$ : Load resistance, current and voltage, $I_{S G}=I_{L}$, $U_{S G}=U_{L}$.

PV cells can be effectively used as a DGR on a MG. However, there are disadvantages such as high installation cost and low energy efficiency. It is more effective to feed the consumers with PV generation at low voltage level. However, due to the fact that PV generation is DC, appropriate power converter circuits will be used for AC - DC power conversion at the specified frequency level. For this reason, the possible contributions of a PV plant to MG may be quite large. Most PV modules are equipped with a maximum power point tracking (MPPT) system that maximizes the power output of the modules by shifting the operating point-related solar radiation [8]. Figure 4 shows the block diagram of the PV section of the MG used in the study. The equations and definitions of this PV system can be found in [11, 12].

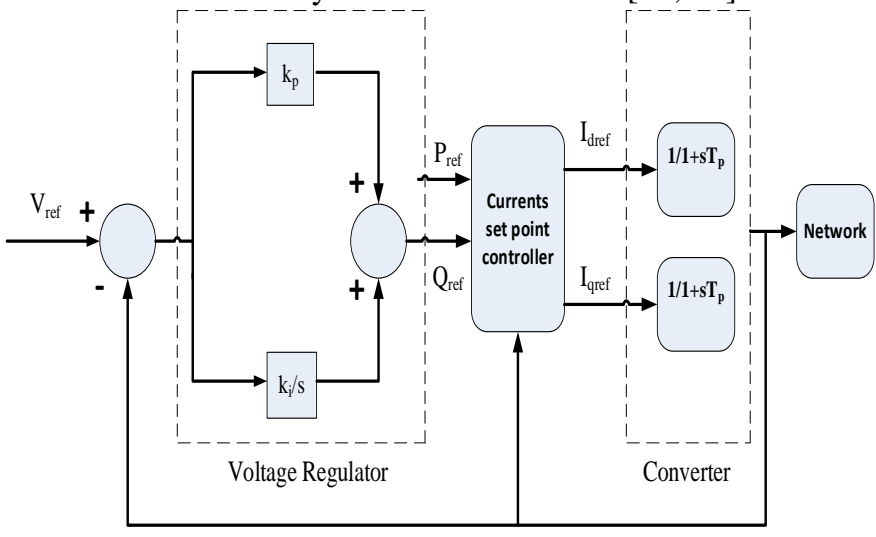

Fig. 4. PV model block diagram

\section{Fuel Cell}

A fuel cell converts the chemical energy of the fuel directly into electrical energy. The fuel cell forms an electrolyte and two electrons (an anode and a cathode) in the same structure. The work is similar to a battery other than storing reagents and products. In the fuel cell, rich fuel with regard to hydrogen and an oxidant (mostly air) are supplied to the one by one 
electrodes. The fuel is given the anode while oxidant is given the cathode and separated by an electrode-electrolyte system. Electrochemical oxidation and reduction occurs on the electrodes to produce electricity. Heat and water are produced as by-products[8].

Fuel cells have high efficiency because they have no moving parts. It can also be shown as another important advantage that it works quietly and does not damage the environment. Figure 5 shows the block diagram of the FC section of the MG used in the study. The equations and definitions of this FC system can be found in source $[6,9,13$, $14]$.

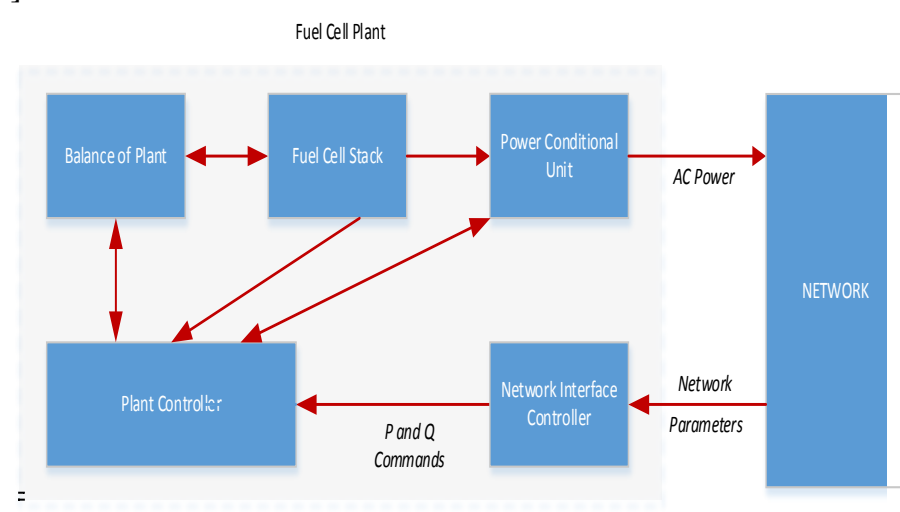

Fig. 5. FC plant model block diagram

IV. SiMULATION RESULTS

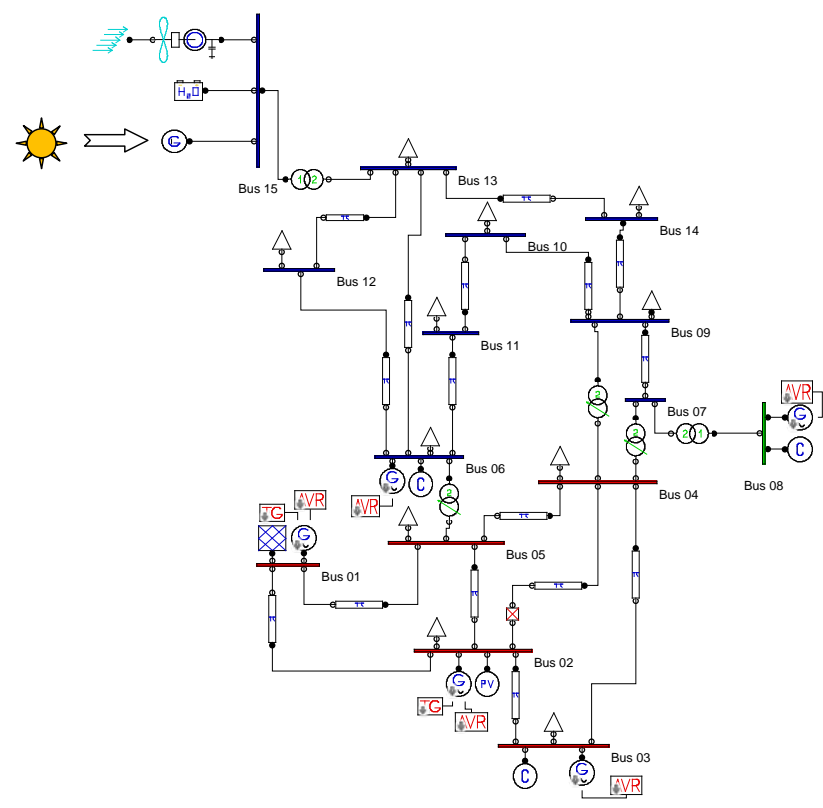

Fig. 6. IEEE 14 bus test system including MG

The test system in which the study is performed is shown in Figure 6. The simulation studies on this paper were carried out in the PSAT [15]. The MG has been integrated in the bus 13 of the IEEE 14-bus system. The power rates of the units forming the MG system have been selected as follows; The fuel cell had $2 \mathrm{MW}$, the PV had $5 \mathrm{MW}$ and the wind model had $10 \mathrm{MW}$ power rates. A short circuit fault which are used commonly power system stability studies was applied to the test system to demonstrate the effect of the MG on the voltage stability of the power system. This fault has been applied on the bus 14 . The fault has occurred in the 2 seconds and it has ended in 2.25 seconds. Figures 7-12 show the simulation results. In each figure, two cases are shown in which the MG is integrated and not integrated. "WITH MG" refers to the state of MG integration while "NO MG" refers to the nonintegration of the MG.

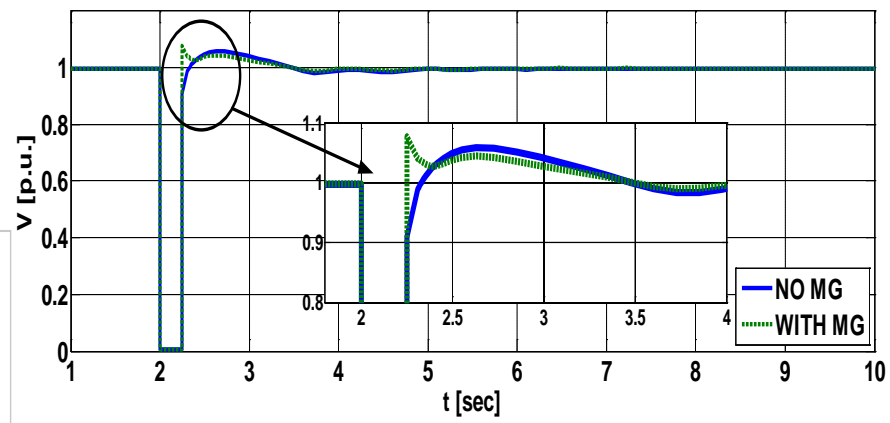

Fig. 7. Voltage of the bus 14 for a 3-phase short circuit fault at bus 14.

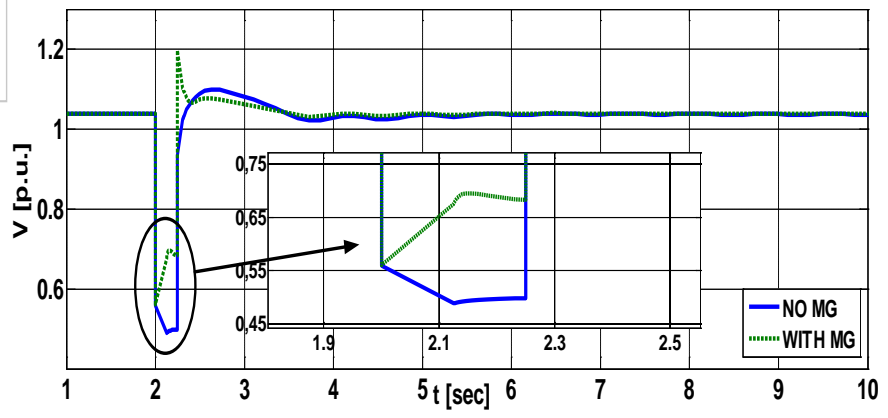

Fig. 8. Voltage of the bus 13 for a 3-phase short circuit fault at bus 14.

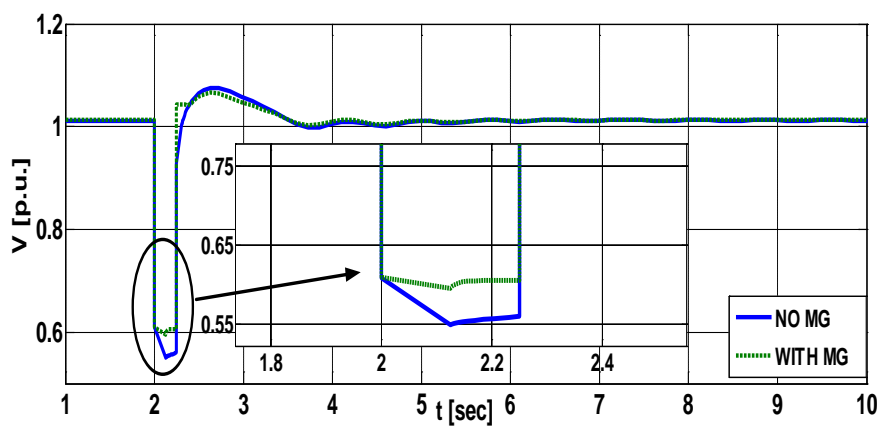

Fig. 9. Voltage of the bus 10 for a 3-phase short circuit fault at bus 14.

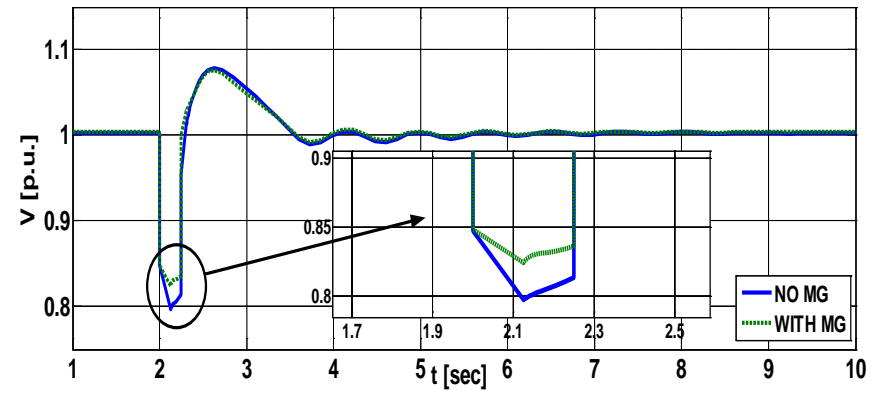

Fig. 10. Voltage of the bus 5 for a 3-phase short circuit fault at bus 14. 


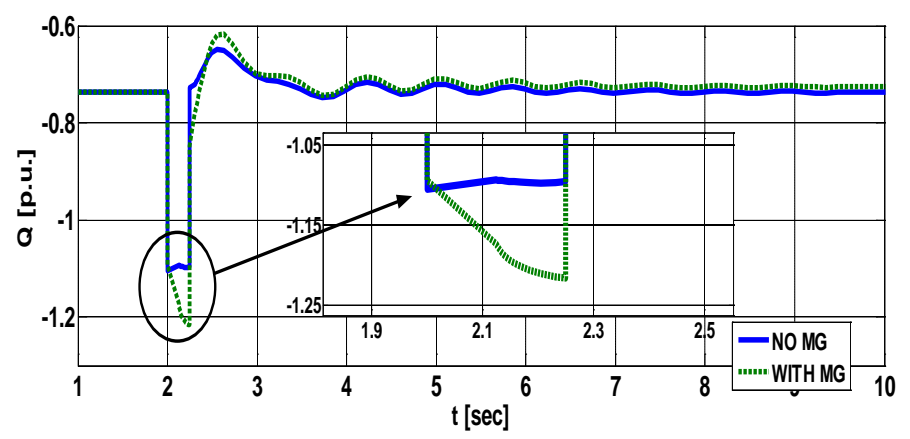

Fig. 11. Q power of bus 14 for 3-phase short circuit fault at bus 14 .

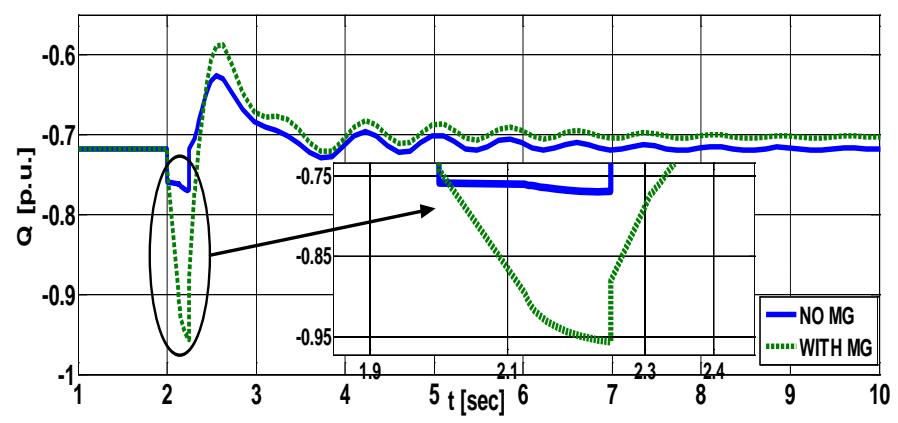

Fig. 12. Q power of bus 13 for 3-phase short circuit fault at bus 14 .

Figure 7-10 shows the variations of the voltage values of some buses during failure, while Figure 11-12 shows the reactive power changes of some buses.

\section{V.CONCLUSION}

In the present study, the influence of a MG on the voltage stability of the power system is investigated. In accordance with this purpose a MG system has been added to the IEEE 14 base test system. The PSAT program was used to perform the analysis studies. A short circuit fault has been applied as a disturbance effect to the IEEE 14 base test system with the system added microgrid created in the PSAT. As a result of this fault, the dynamic voltage stability changes of the system have been investigated for 2 systems.

The dynamic response time of the power system with MG is much faster than the basic state system. This system also accesses the steady state in a shorter time than the basic system. Buses voltage of power system with the MG has better values than the basic state after the steady state has been reached. The reactive power changes of the buses are parallel to the change of the voltage values. The positive effects of the MG on the voltage stability of power system are also seen in the reactive power changes.

\section{REFERENCES}

S. M. Sharkh, M. A. Abu-Sara, G. I. Orfanoudakis, and B. Hussain, Power electronic converters for microgrids: John Wiley \& Sons, 2014.

[2] N. Hatziargyriou, Microgrids Architectures and Control. United Kingdom: John Wiley \& Sons Ltd, 2014.

[3] T. Ding, G. Wang, and H. Li, "Dynamic modeling and simulation analysis on micro-grid based on DIgSILENT," in Advanced Power System Automation and Protection (APAP), 2011 International Conference on, 2011, pp. 1240-1245.
[4] P. Kundur, J. Paserba, V. Ajjarapu, G. Andersson, A. Bose, C. Canizares, et al., "Definition and classification of power system stability IEEE/CIGRE joint task force on stability terms and definitions," IEEE Transactions on Power Systems, vol. 19, pp. 1387-1401, 2004.

[5] H. Khoshkhoo and S. M. Shahrtash, "Fast online dynamic voltage instability prediction and voltage stability classification," IET Generation, Transmission \& Distribution, vol. 8, pp. 957-965, 2014.

[6] F. Milano. (2008). Power System Analysis Toolbox Documentation for PSAT version 2.0.0.

[7] E. Özdemir, "Dağılmış Enerji Üretim Sistemleri ve Yardımcı Hizmetler," presented at the 12. Elektrik Elektronik Bilgisayar ve Biyomedikal Mühendisliği Ulusal Kongresi, Eskişehir, Türkiye, 2007.

[8] S. Chowdhury and P. Crossley, Microgrids and active distribution networks: The Institution of Engineering and Technology, 2009.

[9] F. Milano, Power System Modelling and Scripting. Springer London Dordrecht Heidelberg New York: Springer, 2010.

[10] J. G. Slootweg, "Wind Power: Modelling and Impact on Power System Dynamics," Ph.D. Ph.D., Delft University of Technology, Delft, Netherlands, 2003.

[11] B. Tamimi, C. Cañizares, and K. Bhattacharya, "Modeling and performance analysis of large solar photo-voltaic generation on voltage stability and inter-area oscillations," in Power and Energy Society General Meeting, 2011 IEEE, 2011, pp. 1-6.

[12] B. Tamimi, C. Cañizares, and K. Bhattacharya, "System Stability Impact of Large-Scale and Distributed Solar Photovoltaic Generation: The Case of Ontario, Canada," IEEE Transactions on Sustainable Energy, vol. 4, pp. 680-688, 2013.

[13] J. Padulles, G. Ault, and J. McDonald, "An integrated SOFC plant dynamic model for power systems simulation," Journal of Power sources, vol. 86, pp. 495-500, 2000.

[14] Y. Zhu and K. Tomsovic, "Development of models for analyzing the load-following performance of microturbines and fuel cells," Electric Power Systems Research, vol. 62, pp. 1-11, 2002.

[15] F. Milano, "An open source power system analysis toolbox," IEEE Transactions on Power systems, vol. 20, pp. 1199-1206, 2005.

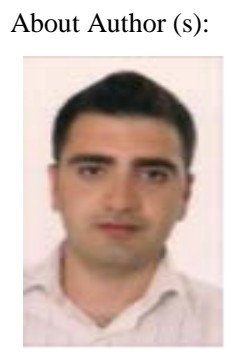

Burak Yildirim was born in Elazı $\breve{g}$, Turkey in 1985. He received the B.Sc. degree from Firat University, Elazığ, Türkiye, and the M.Sc. degree from Tunceli University, Tunceli, Türkiye in 2006 and 2013, respectively, all in Electrical and Electronics Engineering. He is currently working toward the Ph.D. degree from the Firat University, Elazı ğ, Turkey.

He is currently a lecturer at Bingol University in the Vocational Schools of Technical Sciences. His research interests are power system stability, control and optimization, and design and analysis of microgrid and smart grid.

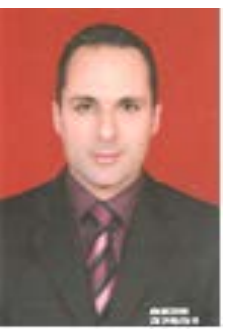

Muhsin Tunay Gencoglu was born in Elazığ, Turkey in 1973. He received the B.Sc., M. Sc. and Ph.D. degrees from Firat University, Elazığ, Turkey in 1994, 1997 and 2003, respectively, all in Electrical and Electronics Engineering. He was a research assistant at Firat University from 1996 to 2003.

He is currently an associate professor in the Department of Electrical and Electronics Engineering. His research interests are High Voltage Insulators, Finite Element Method, Power Transmission and 